Research Article

\title{
Experimental Research on Fatigue Properties of X80 Pipeline Steel for Synthetic Natural Gas Transmission
}

\author{
Li Yan-hua, ${ }^{1,2}$ Feng Hui, ${ }^{1,2}$ Chi Qiang $\mathbb{D}^{1,2}$ Fei Fan,' Gao Xiong-xiong, ${ }^{1,2}$ Li Wei-wei, ${ }^{1,2}$ \\ Xu Xiao-feng, ${ }^{2}$ Chen Hong-yuan, ${ }^{1,2}$ and Zhang Hua ${ }^{2}$ \\ ${ }^{1}$ State Key Laboratory for Performance and Structure Safety of Petroleum Tubular Goods and Equipment Materials, \\ Xi'an 710077, China \\ ${ }^{2}$ Tubular Goods Research Institute of China National Petroleum Corporation, Xi'an 710077, China \\ ${ }^{3}$ Petrochina Beijing Gas Pipeline Company, Beijing 100101, China
}

Correspondence should be addressed to Chi Qiang; chiq@cnpc.com.cn

Received 2 November 2020; Revised 11 November 2020; Accepted 11 November 2020; Published 27 January 2021

Academic Editor: Shun-Peng Zhu

Copyright (C) $2021 \mathrm{Li}$ Yan-hua et al. This is an open access article distributed under the Creative Commons Attribution License, which permits unrestricted use, distribution, and reproduction in any medium, provided the original work is properly cited.

\begin{abstract}
In recent years, many synthetic natural gas demonstration projects have been put into operation all over the world, and hydrogen is usually contained in synthetic natural gas. X80 is the most commonly used high-grade pipeline steel in the construction of natural gas pipelines. The compatibility between high-grade pipeline steel and hydrogen directly affects safety and reliability of long-distance pipelines. Therefore, in order to study the effect of hydrogen content on fatigue properties of high-grade pipeline steel, fatigue specimens were taken from base metal, spiral welds, and girth weld of submerged arc spiral welded pipes, respectively. Specifically, the total pressure was $12 \mathrm{MPa}$ and hydrogen content was from 0 to $5 \mathrm{vol} \%$. Experimental results indicate that the hydrogen significantly increases the fatigue crack growth rate for both base metal, spiral weld, and heat-affected zone of X80 pipeline steel for about ten times compared with reference environment nitrogen, hydrogen would greatly reduce the fatigue life of the X80 pipeline steel, and the fatigue lifetime would decrease with the increase in hydrogen volume fraction. In order to ensure the safe operation of SNG pipeline, the hydrogen content should be controlled as low as possible.
\end{abstract}

\section{Introduction}

With the substantial increase in energy demand, many countries have increased the exploitation of oil and gas resources to meet the demands of the market. Although oil and gas will be purified before long-distance pipeline transportation, there are still high content of corrosive medium in oil and gas under certain conditions. In addition, with the environmental pollution problem becoming increasingly serious, the clean utilization of fossil energy such as coal is imminent. The feasibility of synthetic natural gas (SNG) technology has been verified in the coal gasification in the United States for 30 years. In recent years, China has also planned some large-scale coal-gasification projects, and pipelines such as Xinjiang-Guangdong-Zhejiang synthetic natural gas pipeline project have been constructed to transport SNG. Compared with the traditional natural gas, SNG usually contains a higher hydrogen content, which brings the problem of the hydrogen embrittlement of pipelines [1-7].

In recent years, in order to prevent pipeline failure caused by hydrogen and ensure the service safety of synthetic natural gas (SNG) transmission, some scholars have begun to study the effect of hydrogen on the mechanical properties of pipeline steel. Many efforts have been devoted to develop high-grade pipeline steel for hydrogen transmission, and the highest pipeline steel grade reaches X80. Nevertheless, the research on girth weld is relatively limited, and in recent years, girth weld is the most vulnerable part of failure in the pipeline system due to structure and other factors. In this regard, this study studied not only the base metal and spiral weld but also girth weld $[8,9]$. Moreover, the composition and microstructure of X80 pipeline steel have changed greatly. Therefore, the most typical X80 pipeline steel for pipeline construction is adopted as the research object in this paper. 
This study attempts to investigate the effect of hydrogen content on fatigue properties of high-grade pipeline steel for SNG transmission. Specifically, fatigue tests on X80 line pipe under different hydrogen contents were conducted on specimens cut from different locations of a typical X80 pipeline, i.e., base metal, spiral weld, and girth weld to study the influence of hydrogen on fatigue properties of highgrade pipeline steel, and the fracture surface of fatigue samples was analyzed; finally, the influence mechanism of hydrogen embrittlement for different locations of highgrade pipeline steel was evaluated.

\section{Experimental Method}

2.1. Materials. Taking a typical X80 spiral welded pipe which has been widely applied for natural gas pipeline construction as a sample, the influence of hydrogen content on fatigue properties of high-grade pipeline steel was studied. Specifically, the size of the X80 pipe is $\Phi 1219 \mathrm{~mm} \times 18.4 \mathrm{~mm}$, and the chemical composition of the material is listed in Table 1.

2.2. Sampling Method. From the pipeline steel test standards, such as API 5L and ASTM A370, the sampling locations are mainly based on the principal stress direction and structural factors, as shown in Figure 1. For the base metal sample, the notched specimens $(\mathrm{N})$ are taken horizontally (the pipe is under the maximum stress in this direction), and the notch direction of compact tensile $(\mathrm{C}(\mathrm{T}))$ samples is parallel to the axial direction. For the spiral weld and girth weld metal samples, the notch direction of the samples is parallel to the weld joint, and the notch center line is located at the welding joint. For the heat-affected zone samples, the notch direction of the $\mathrm{C}(\mathrm{T})$ sample is parallel to the weld joint, and the distance from the notch center line to the welded joint is $1 \mathrm{~mm}$. The requirements of ASME VIII-3 KD 10 should be met at the same time [10].

\subsection{Test Methods}

2.3.1. Test Environment. According to the composition statistics of hydrogen content of SNG, four hydrogen contents are adopted, i.e., $0 \%$ for reference environment, $1 \%$ for the highest measured hydrogen content, $2.2 \%$ for the highest design hydrogen content, and $5 \%$ for the maximum allowable value of hydrogen content in synthetic natural gas standards. The test environment is presented in Table 2.

The purity of nitrogen and hydrogen adopted in this test meets the high purity grade (99.999\%) of National Standard of China GB/T 8979-2008 "pure nitrogen, high purity nitrogen, and ultrapure nitrogen" and National Standard of China GB/T 3634.2-2011 "pure hydrogen, highly pure hydrogen, and ultrapure hydrogen," respectively. In particular, the test was carried out at room temperature $\left(25^{\circ} \mathrm{C}\right)$.

2.3.2. Test Equipment. The Instron universal testing machine with high-pressure hydrogen compatibility was adopted to carry out the fatigue test in the high-pressure gas environment containing hydrogen. In particular, the tests
TABle 1: Chemical composition of the X80 spiral welded pipe (wt.\%).

\begin{tabular}{lccccc}
\hline $\mathrm{C}$ & $\mathrm{Nb}$ & $\mathrm{V}$ & $\mathrm{Ti}$ & $\mathrm{Cu}$ & $\mathrm{Cr}$ \\
\hline 0.06 & 0.07 & 0.03 & 0.02 & 0.01 & 0.26 \\
\hline
\end{tabular}

can be carried out in high-pressure hydrogen environment including fatigue crack growth rate test, low cycle fatigue test, and fracture toughness test.

2.3.3. Procedures of Low Cycle Fatigue Test. Based on ASTM $\mathrm{E} 466$ and GB/T 34542.2, the notched round bar specimens, as shown in Figure 2, were placed in the four environments, respectively. The uniaxial tension cyclic load was applied to the specimen with a stress ratio of 0.1 . The minimum and maximum forces were $2 \mathrm{kN}$ and $20 \mathrm{kN}$, respectively, and the loading frequency was $1 \mathrm{~Hz}$. Then, the number of cycles to failure (fatigue life) of X80 pipeline steel in high-pressure hydrogen environment was obtained [11].

\subsubsection{Procedures of Fatigue Crack Growth Rate Test.} Based on ASTM E647, ASME VIII-3 KD 10, and GB/T 34542.2 , the precrack was introduced on the $\mathrm{C}(\mathrm{T})$ specimen, as shown in Figure 3, in air. The sinusoidal waveform cyclic load was applied to the specimen with a stress ratio of 0.1 . The loading frequency was $5 \mathrm{~Hz}$, and the initial force was $25 \mathrm{kN}$. The periodic load reduction process is tabulated in Table 3. After the crack length reached $3.0 \mathrm{~mm}$, the specimens were placed in high-pressure environment with different hydrogen contents, the load frequency was changed to $1 \mathrm{~Hz}$, and the load force was kept at $19 \mathrm{kN}$. Then, the relationship between the crack length and the stress intensity factor with the number of loading cycles can be obtained and based on which the fatigue crack growth rate of the X80 pipeline steel in different environments was obtained.

\section{Test Results}

3.1. Low Cycle Fatigue Test Result. The fatigue results of the base metal are shown in Figure 4. It can be obtained from Figure 4 that the average fatigue lives of base metal of X80 pipeline steel under reference environment and other environments containing hydrogen are 4274, 1461, 1198, and 398.5 times, respectively. It can be concluded that hydrogen greatly reduces the fatigue life of the X80 base metal, and the fatigue life would decrease with the increase in hydrogen volume fraction. Specifically, compared with reference environment, the relative cycle times in $1 \mathrm{vol} \% \mathrm{H}_{2}, 2.2 \mathrm{vol} \% \mathrm{H}_{2}$, and $5 \mathrm{vol} \% \mathrm{H}_{2}$ environment are $34.18 \%, 28.03 \%$, and $9.32 \%$, respectively. However, the degradation degree of fatigue performance is related to the stress concentration factor of notched round bar specimen.

Figure 5 shows the fatigue results of the spiral weld, and the average fatigue life of X80 spiral weld under reference environment and other environments containing hydrogen is $43611,717.5,645.5$, and 283.5 times, respectively. It can be concluded that hydrogen greatly reduces the fatigue life of the X80 spiral weld. Specifically, compared with reference 


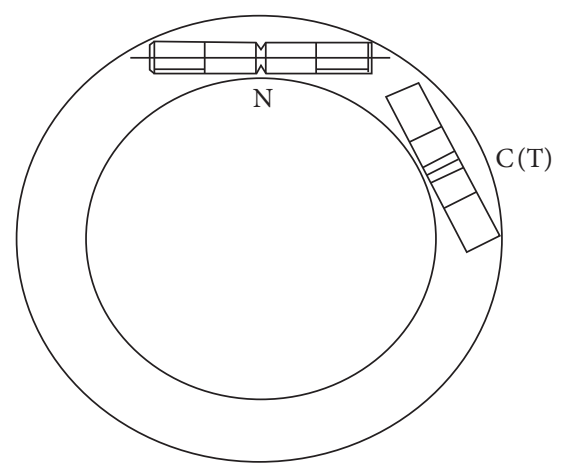

(a)

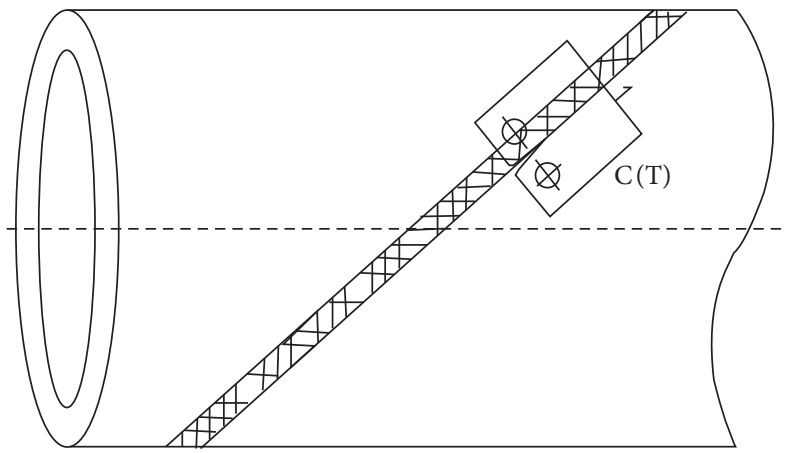

(c)

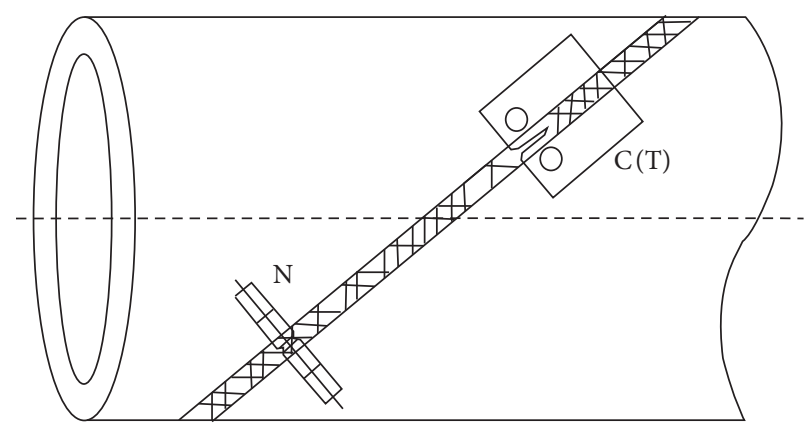

(b)

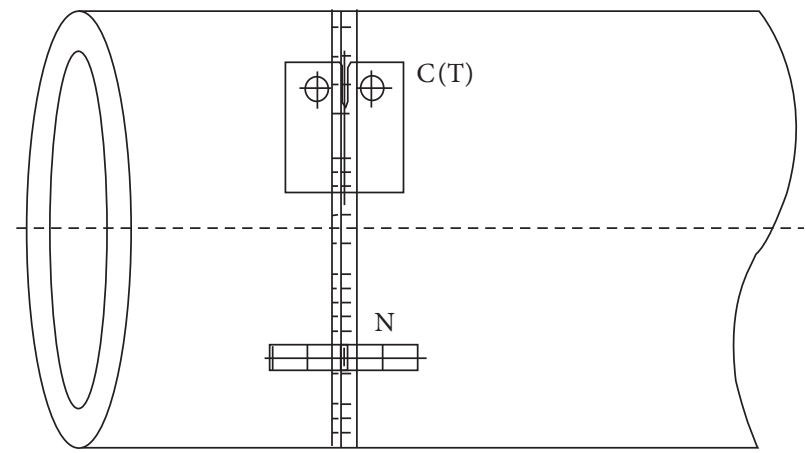

(d)

FIGURE 1: Sampling locations: (a) sampling of base metal; (b) sampling of spiral weld; (c) sampling of heat-affected zone; (d) sampling of girth weld.

TABLE 2: The test environment.

\begin{tabular}{lccc}
\hline Test environment no. & Hydrogen content & Nitrogen content & Total pressure \\
\hline 1 & $0 \mathrm{vol} \%$ & $100 \mathrm{vol} \%$ & $99 \mathrm{vol} \%$ \\
2 & $1 \mathrm{vol} \%$ & $97.8 \mathrm{vol} \%$ & $12 \mathrm{MPa}$ \\
3 & $2.2 \mathrm{vol} \%$ & $95 \mathrm{vol} \%$ & \\
4 & $5 \mathrm{vol} \%$ & & \\
\hline
\end{tabular}

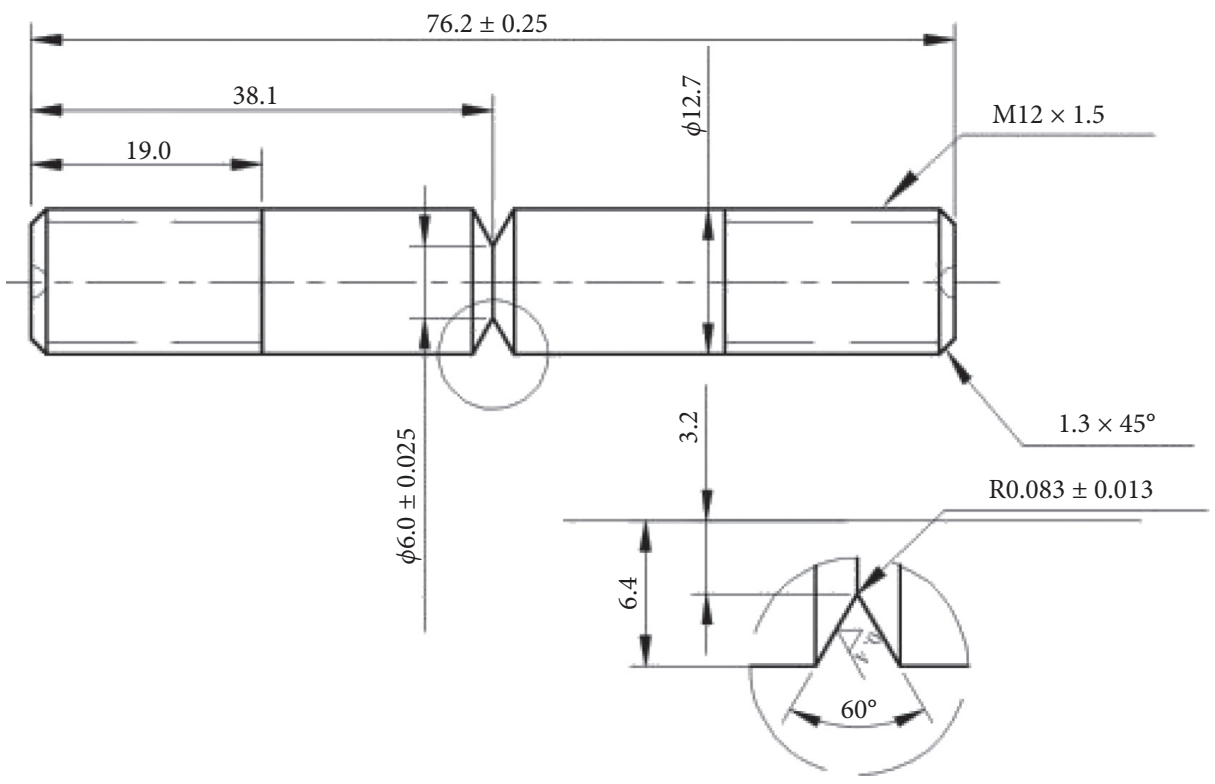

Figure 2: Dimensions of notched fatigue specimens. 


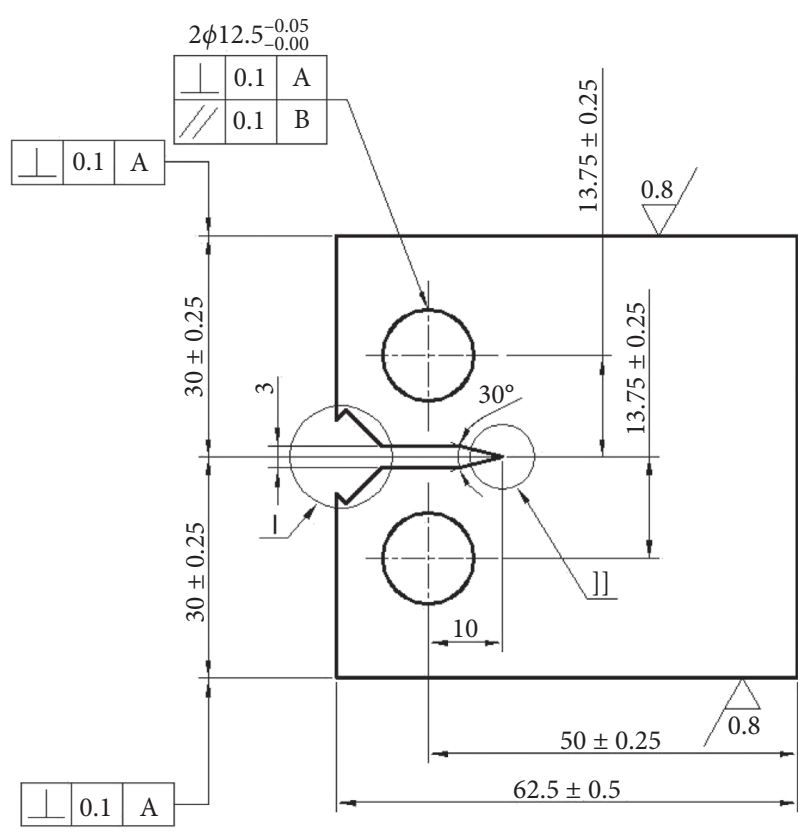

Figure 3: Dimensions of $\mathrm{C}(\mathrm{T})$ specimens.

TABLE 3: The periodic load reduction process.

\begin{tabular}{lcccc}
\hline Load force $(\mathrm{kN})$ & 25 & 23 & 21 & 19 \\
\hline Crack length $(\mathrm{mm})$ & 0 & 1.0 & 2.0 & 3.0 \\
\hline
\end{tabular}

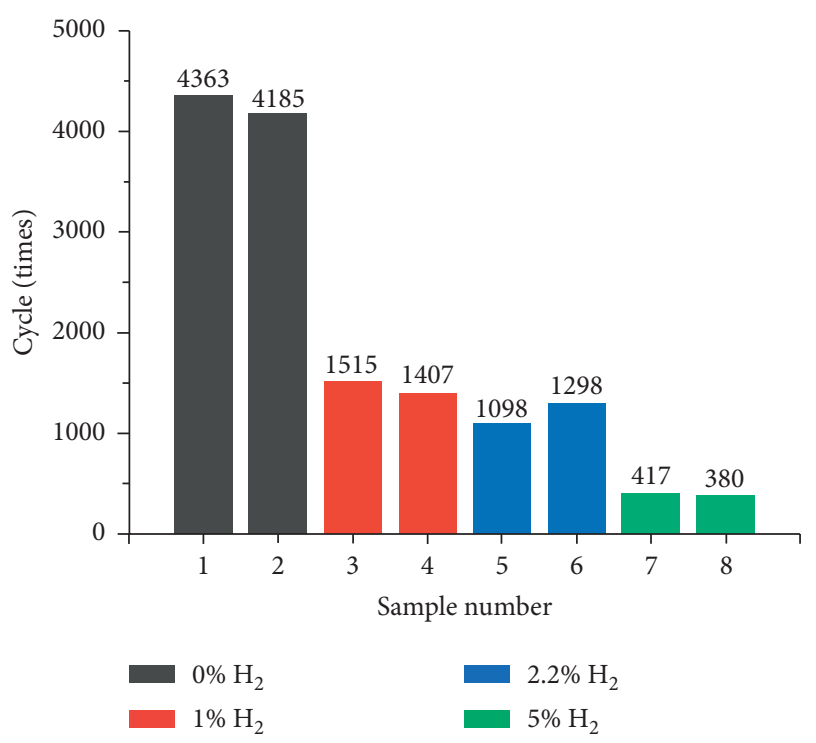

FIGURE 4: Fatigue life of X80 base metal.

environment, the relative cycle times in $1 \mathrm{vol} \% \mathrm{H}_{2}, 2.2 \mathrm{vol} \%$ $\mathrm{H}_{2}$, and $5 \mathrm{vol} \% \mathrm{H}_{2}$ environment are $19.87 \%, 17.88 \%$, and $7.85 \%$, respectively.

The fatigue life obtained from the girth weld fatigue test is shown in Figure 6. From Figure 6, the average fatigue life of girth weld of X80 pipeline steel under reference environment and other environments containing hydrogen is $2546.5,658.5,434.5$, and 304.5 times, respectively. It can be

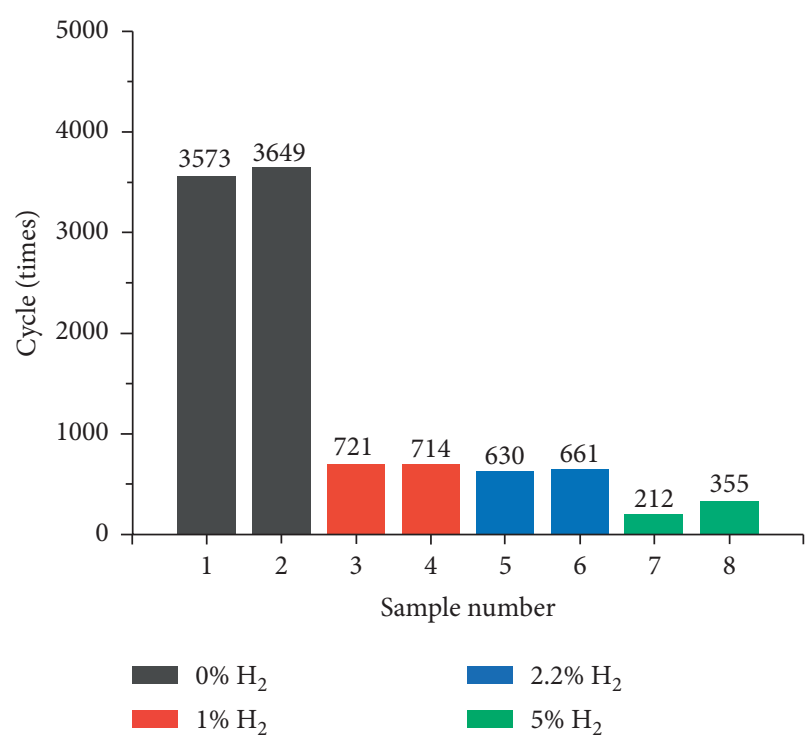

Figure 5: Fatigue life of X80 spiral weld.

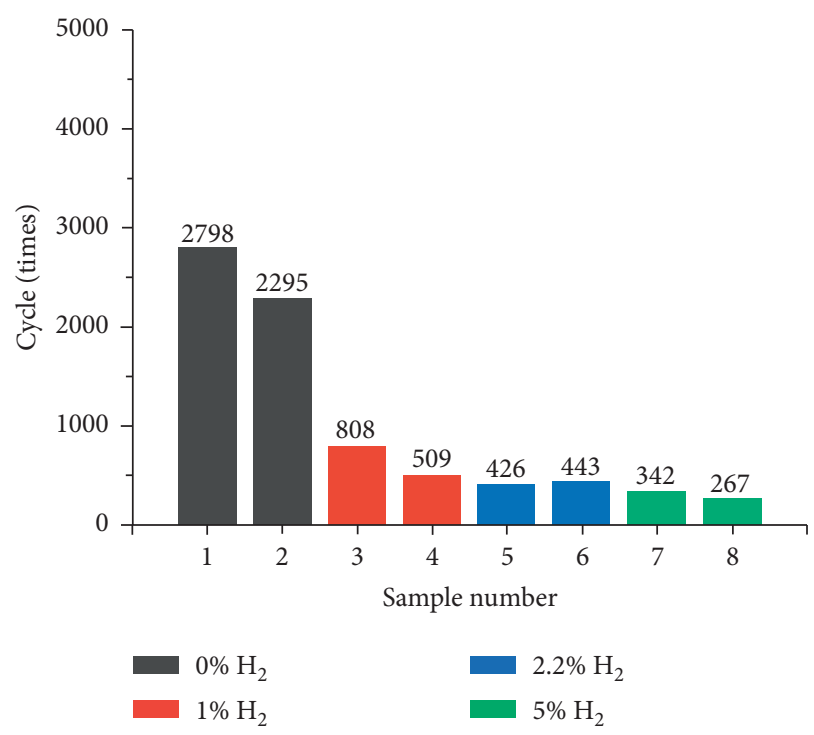

Figure 6: Fatigue life of X80 girth weld.

concluded that hydrogen greatly reduces the fatigue life of the X80 girth weld, and the cycle time would decrease with the increase in hydrogen volume fraction. Specifically, compared with reference environment, the relative cycle times in $1 \mathrm{vol} \% \mathrm{H}_{2}, 2.2 \mathrm{vol} \% \mathrm{H}_{2}$, and $5 \mathrm{vol} \% \mathrm{H}_{2}$ environment are $25.86 \%, 17.06 \%$, and $11.96 \%$, respectively.

3.2. Fatigue Crack Growth Rate Test Result. The fatigue crack growth rate obtained from the fatigue crack growth rate test of the X80 base metal is shown in Figure 7. It can be concluded from Figure 7 that the fatigue crack growth rate of the base metal in the environments containing hydrogen increases obviously, the fatigue crack growth rate in 1vol\% $\mathrm{H}_{2}$ is about 7.2 times than that in nitrogen environment, the fatigue crack growth rate in $2.2 \mathrm{vol} \% \mathrm{H}_{2}$ is about 11.2 times, 


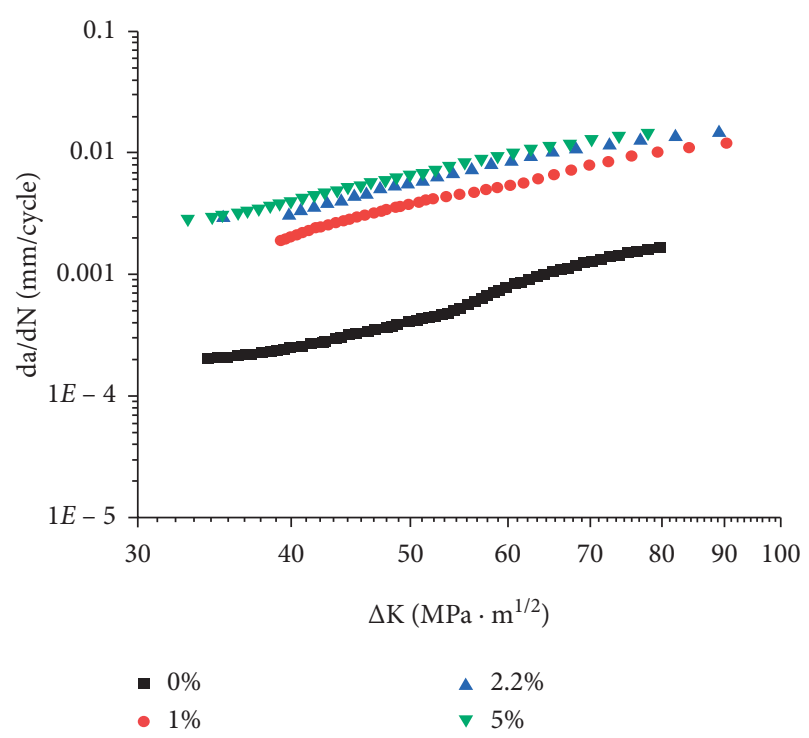

FIGURE 7: Fatigue crack growth rate of X80 base metal.

and the fatigue crack growth rate in $5 \mathrm{vol} \% \mathrm{H}_{2}$ is about 13.5 times. Meanwhile, the fatigue crack growth rate increases slightly with the increase in hydrogen volume fraction.

Figure 8 shows fatigue crack growth rate of the X80 spiral weld. From Figure 8, the results are similar to those of base metal. It can be concluded that the fatigue crack growth rate of the spiral weld in the environments containing hydrogen increases obviously, and the fatigue crack growth rate in 1vol $\% \mathrm{H}_{2}$ is about 6.2 times of that in nitrogen environment, the fatigue crack growth rate in $2.2 \mathrm{vol} \% \mathrm{H}_{2}$ is about 6.8 times, and the fatigue crack growth rate in $5 \mathrm{vol} \% \mathrm{H}_{2}$ is about 8.4 times. Meanwhile, the fatigue crack growth rate increases slightly with the increase in hydrogen volume fraction.

The fatigue crack growth rate obtained from the fatigue crack growth rate test of the X80 heat-affected zone is shown in Figure 9. It can be concluded from Figure 9 that the results are similar to those of base metal as well. The fatigue crack growth rate of the heat-affected zone in the environments containing hydrogen increases obviously, the fatigue crack growth rate in $1 \mathrm{vol} \% \mathrm{H}_{2}$ is about 7.9 times than that in nitrogen environment, the fatigue crack growth rate in $2.2 \mathrm{vol} \% \mathrm{H}_{2}$ is about 8.4 times, and the fatigue crack growth rate in $5 \mathrm{vol} \% \mathrm{H}_{2}$ is about 9.3 times. Meanwhile, the fatigue crack growth rate increases slightly with the increase in hydrogen volume fraction.

It can be obtained from Figure 10 that the fatigue crack growth rate of the girth weld in the environments containing hydrogen increases obviously, the fatigue crack growth rate in 1 vol\% $\mathrm{H}_{2}$ is about 8.5 times than that in nitrogen environment, the fatigue crack growth rate in $2.2 \mathrm{vol} \% \mathrm{H}_{2}$ is about 11.3 times, and the fatigue crack growth rate in 5vol\% $\mathrm{H}_{2}$ is about 13.1 times. Meanwhile, the fatigue crack growth rate increases slightly with the increase in hydrogen volume fraction. However, in the environment of $2.2 \mathrm{vol} \% \mathrm{H}_{2}$ and $5 \mathrm{vol} \% \mathrm{H}_{2}$, there are obvious fluctuations on the fatigue crack growth rate curve, which may be related to the

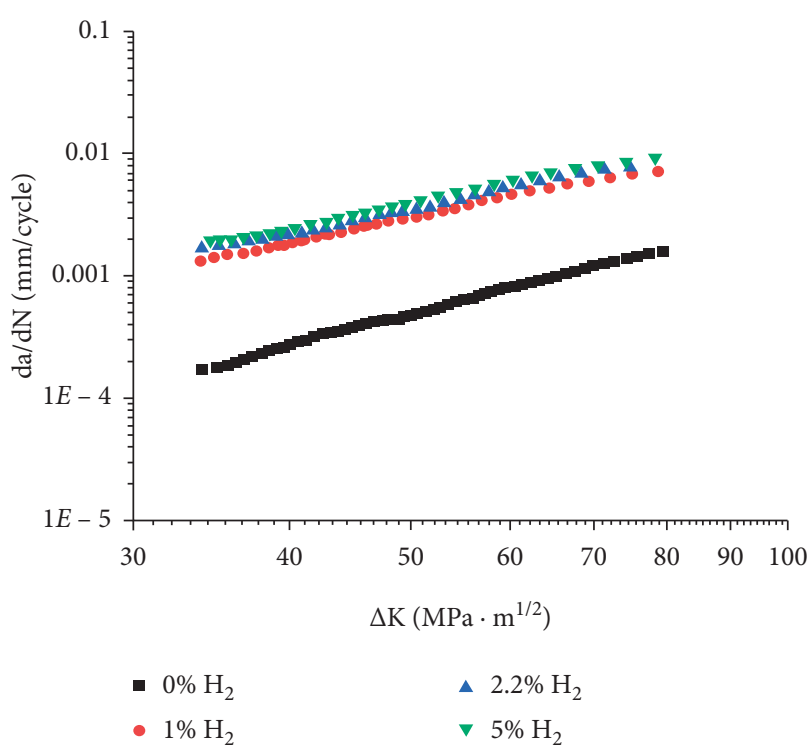

Figure 8: Fatigue crack growth rate of X80 spiral weld.

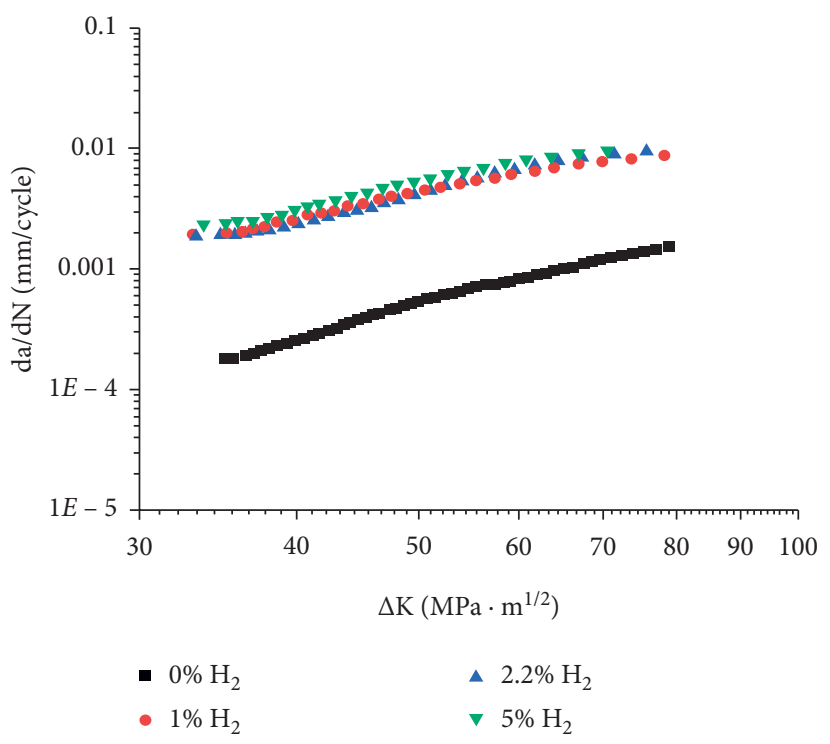

FIGURE 9: Fatigue crack growth rate of X80 heat-affected zone.

inhomogeneous mechanical properties and defect locations of girth weld.

\section{Discussion}

Based on the obtained fatigue lives of specimens cutting from different sampling locations, the influence of sample locations on fatigue life of X80 pipeline steel was studied. As shown in Figures 4 10, the fatigue lives of X80 base metal, spiral weld, and girth weld under different environments are presented. Results indicate that hydrogen greatly reduces the fatigue life for the X80 base metal, spiral weld, and girth weld. Moreover, the fatigue performance of girth weld is the worst in the reference environment, and the fatigue performance of base metal is the best in the environments 


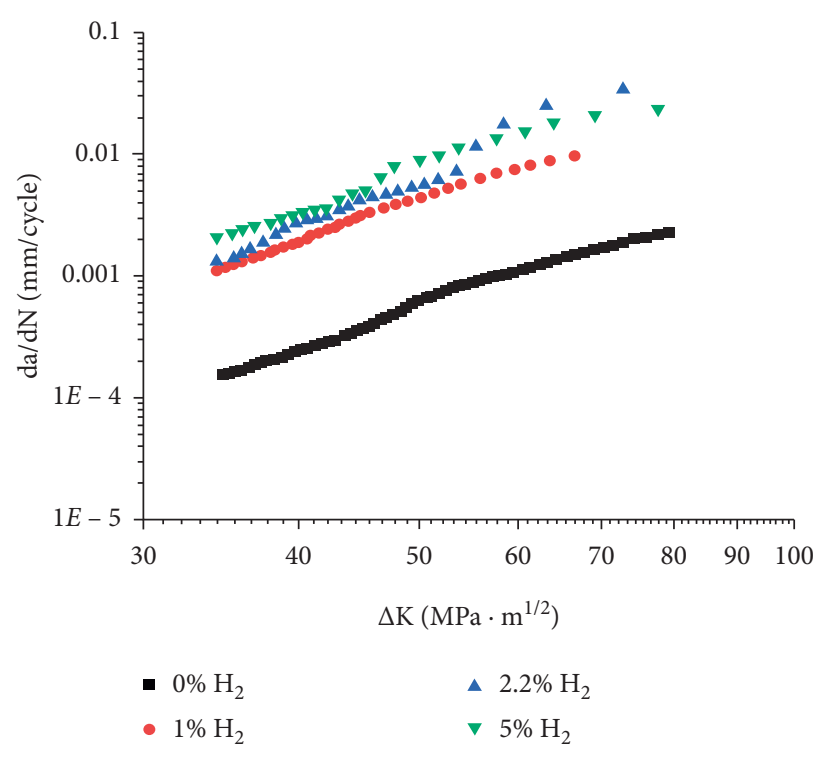

FIGURE 10: Fatigue crack growth rate of X80 girth weld.

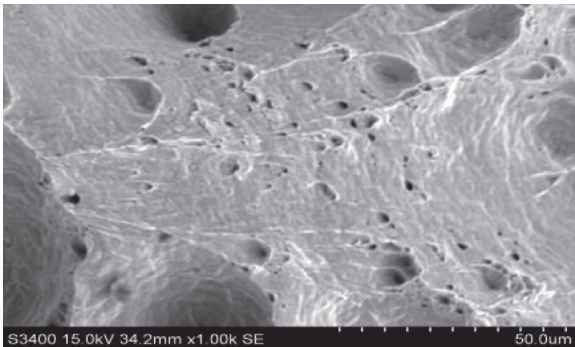

(a)

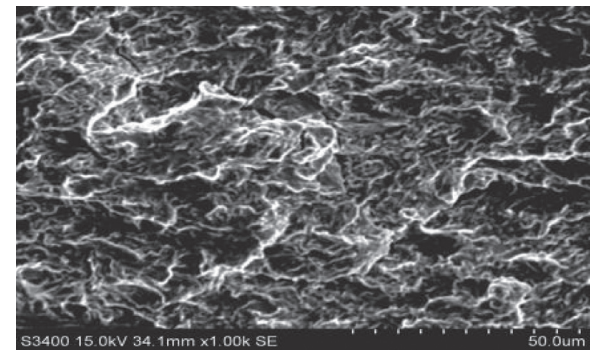

(b)

FIGURE 11: Fracture morphology of fatigue specimen of base metal: (a) reference environment; (b) environment containing $5 \%$ hydrogen.

containing $5 \mathrm{vol} \% \mathrm{H}_{2}$; the fatigue cycles of girth weld and spiral weld are similar in the environments containing hydrogen.

In the environment containing hydrogen, the order of fatigue crack growth rate from large to small is girth weld, base metal, heat-affected zone, and spiral weld, respectively. And the difference in fatigue crack growth rate would be more obvious as the hydrogen volume fraction increases.

It can be concluded that microstructure and hydrogen permeation characters pose great influence on the fatigue crack growth rate $[12,13]$. Moreover, the hydrogen permeation and diffusion behavior are mainly controlled by chemical composition, lattice defects, and microstructure. The fracture morphology of fatigue specimens from different locations of X80 pipeline steel is presented in Figures 11-13. The microstructure of base metal is mainly composed of banded and acicular ferrite, the microstructure of spiral weld is mainly composed of acicular ferrite and long strip proeutectoid ferrite, and the microstructure of heat-affected zone is mainly composed of fine-grained bainite. The grain size of spiral weld and heat-affected zone is very fine, which reduces the hydrogen permeation and diffusion rate to a certain extent. Compared with fine-grained bainite, acicular ferrite has higher toughness, and many large angle grain boundaries may hinder the crack growth. Therefore, the spiral weld has the least fatigue crack growth rate. In addition, the welding material used for spiral weld may have better crack propagation resistance than the base metal.

The fatigue crack growth rate of girth weld is more sensitive than other locations, which may be related to the inhomogeneous mechanical properties and defect distributions [14-23], as shown in Figures 14-17.

As shown in Figure 15, the microstructure of the girth weld consists of bainite ferrite, which grows from the grain boundary to intragranular in parallel ferrite laths. The ferrite bundles of different orientations divide the prior austenite grains into different regions. There are some ferrite bundles passing through the prior austenite grains, which is detrimental to crack propagation resistance due to long slip length. The microstructure of HAZ of girth weld is shown in Figure 16. The size of prior austenite is significantly reduced compared to the weld. The size of prior austenite grains is about $20 \mu \mathrm{m}$. The microstructure of position 3 of girth weld consists of granular bainite and ferrite, as shown in Figure 17. The contour of prior austenite grains is not clear. The 


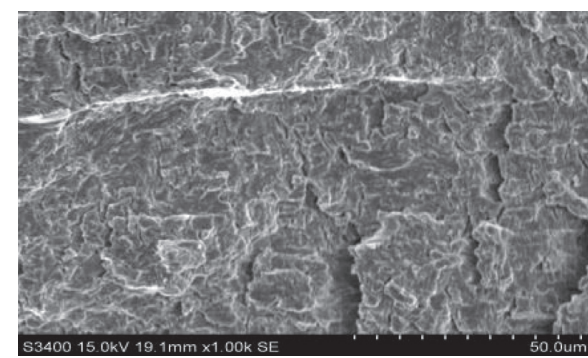

(a)

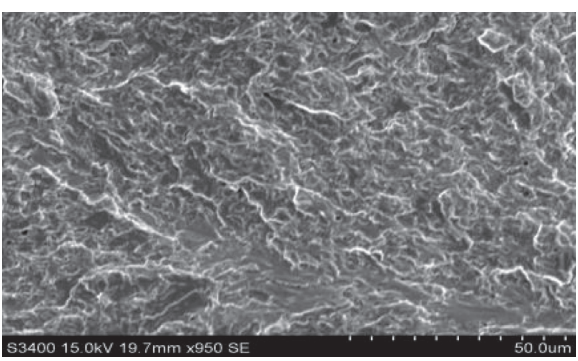

(b)

FIGURE 12: Fracture morphology of fatigue specimen of spiral weld: (a) reference environment; (b) environment containing $5 \%$ hydrogen.

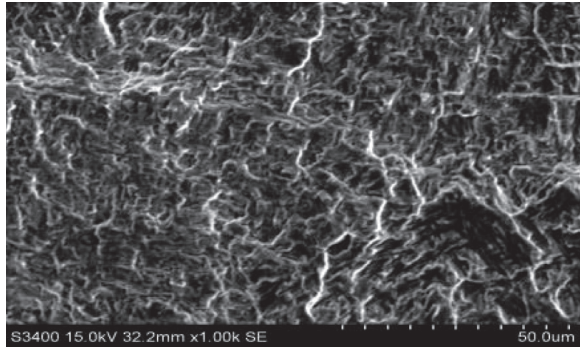

(a)

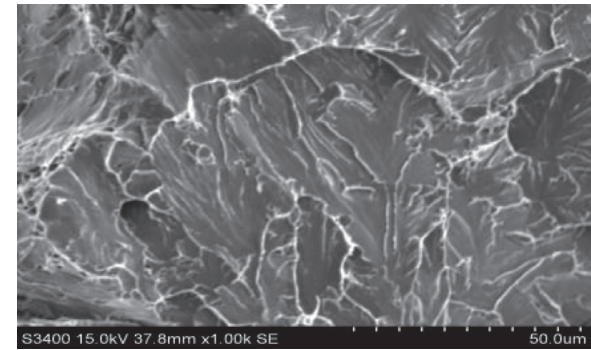

(b)

FIGURE 13: Fracture morphology of fatigue specimen of girth weld: (a) reference environment; (b) environment containing 5\% hydrogen.

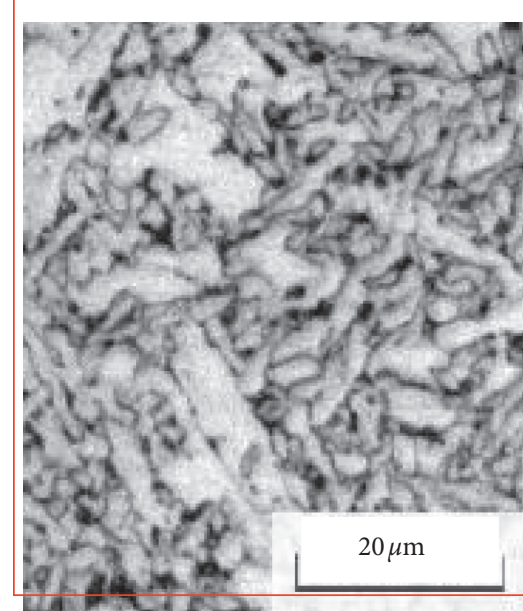

(a)

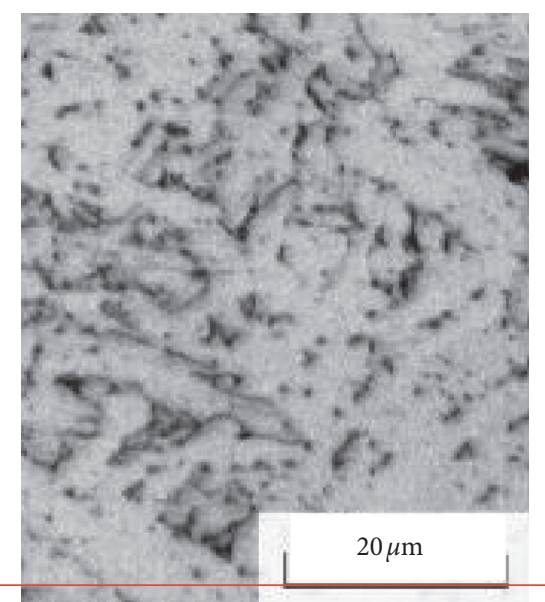

(b)

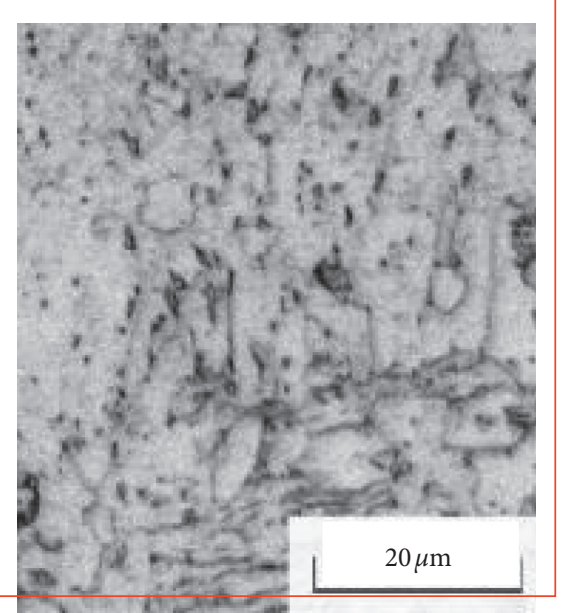

(c)

FIGURE 14: Microstructure characteristics of girth weld on different positions: (a) backing weld; (b) filling weld; (c) covering weld.

size of average grain is about $5 \mu \mathrm{m}$, which has better mechanical properties than weld and HAZ.

As a result, a lot of fluctuations appear on the fatigue crack growth curve. Some studies had shown that the residual stress in girth weld can accelerate the fatigue crack growth [24-27]. In addition, if the effect of residual stress is ignored, the fatigue crack growth rate of girth weld will approach to that of base metal. Therefore, in the process of operation and maintenance of SNG pipeline, girth weld should be one of the most concerned parts. Moreover, in the process of pipeline construction, girth weld defects and hydrogen embrittlement sensitivity of welding materials should be strictly controlled, and good counterpart of pipes should be realized to control the structural stress at the lowest level. 


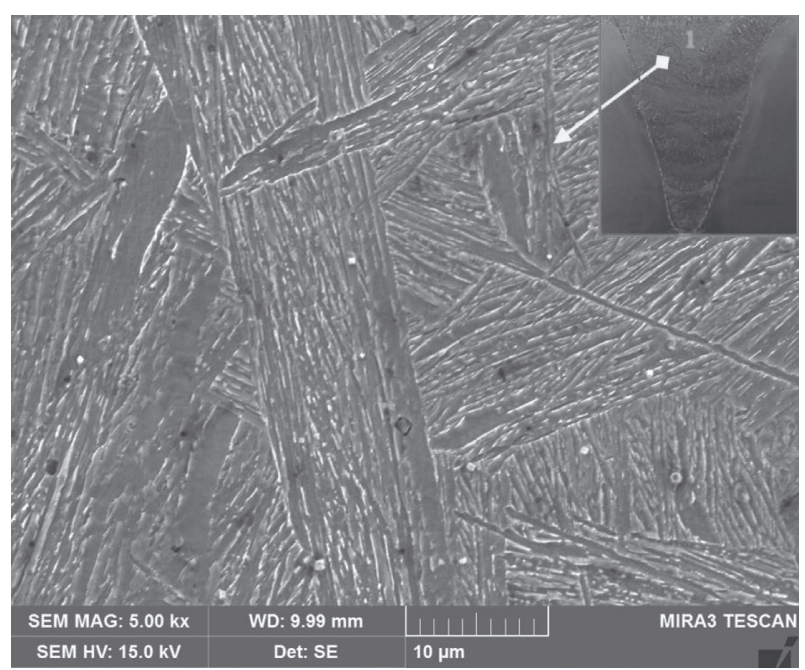

FIGURE 15: SEM of position 1 of X80 pipeline girth weld.

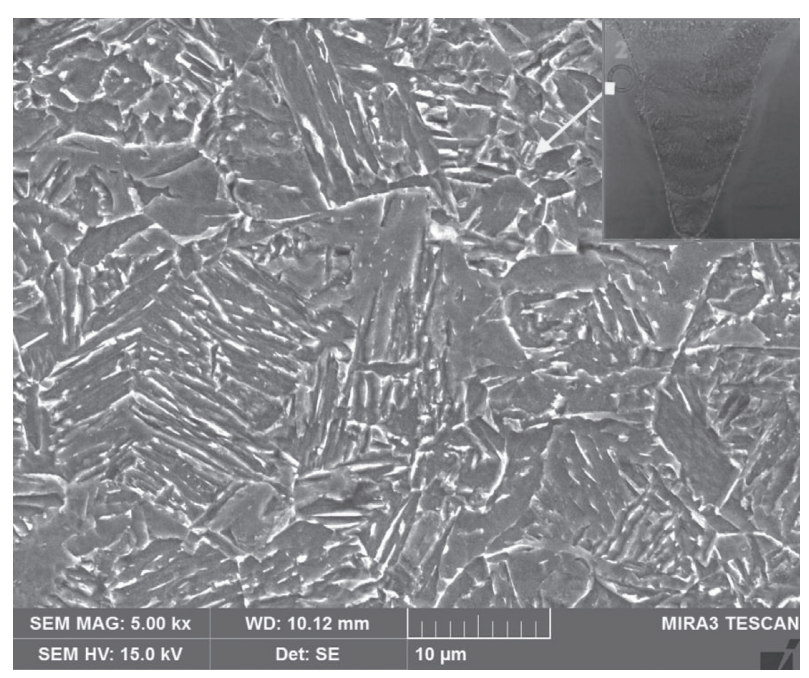

FIgURE 16: SEM of position 2 of X80 pipeline girth weld.

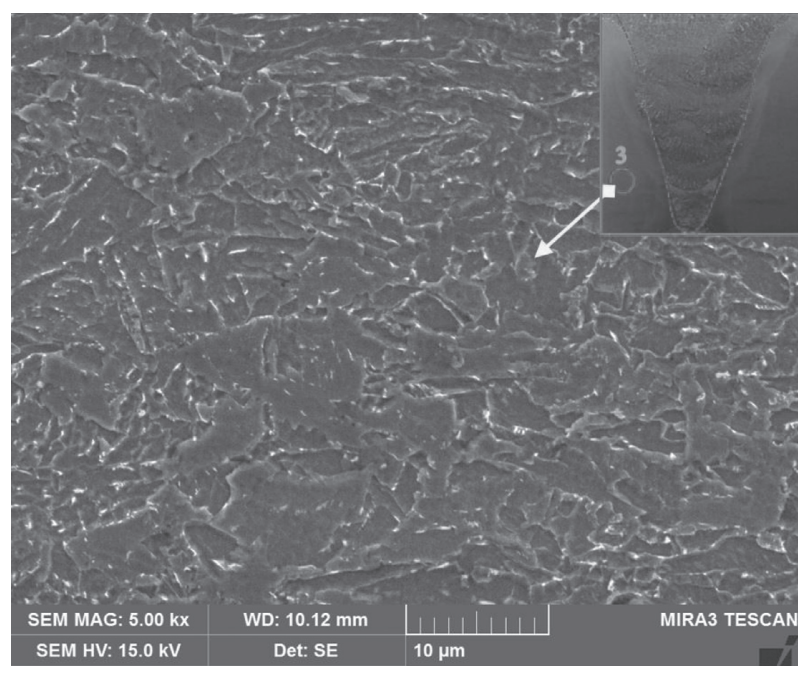

FIGURE 17: SEM of position 3 of X80 pipeline girth weld.

\section{Conclusions}

Hydrogen greatly reduces the fatigue life of the X80 base metal, and the fatigue lifetime would decrease with the increase in hydrogen volume fraction. Hence, in order to ensure the safe operation of SNG pipeline, the hydrogen content should be controlled as low as possible. The order of fatigue crack growth rate from large to small is girth weld, base metal, heat-affected zone, and spiral weld, respectively, and in the process of operation and maintenance of synthetic natural gas pipeline, girth weld should be one of the most concerned parts.

The difference in fatigue crack growth rate at different locations is related to the difference in microstructure and hydrogen permeation characters. The fatigue crack growth rate of girth weld is more sensitive than other locations, which may be related to the inhomogeneous mechanical properties and defect distributions.

\section{Data Availability}

The data used to support the findings of this study are included within the article.

\section{Conflicts of Interest}

The authors declare that they have no conflicts of interest.

\section{Acknowledgments}

This work was supported by the China National Petroleum Corporation Major Project (2016B-3002) and Shaanxi Province Innovation Talent Promotion Plan (2018KJXX086).

\section{References}

[1] M. A. Mohtadi-Bonab, J. A. Szpunar, and S. S. Razavi-Tousi, "Hydrogen induced cracking susceptibility in different layers of a hot rolled X70 pipeline steel," International Journal of Hydrogen Energy, vol. 38, no. 31, pp. 13831-13841, 2013.

[2] A. Torresislas, V. Salinasbravo, J. Albarran, and J. Gonzalezrodriguez, "Effect of hydrogen on the mechanical properties of X-70 pipeline steel in diluted solutions at different heat treatments," International Journal of Hydrogen Energy, vol. 30, no. 12, pp. 1317-1322, 2005.

[3] M. A. Arafin and J. A. Szpunar, "Effect of bainitic microstructure on the susceptibility of pipeline steels to hydrogen induced cracking," Materials Science and Engineering: A, vol. 528, no. 15, pp. 4927-4940, 2011.

[4] C. Zhang and Y. F. Cheng, "Corrosion of welded X100 pipeline steel in a near-neutral $\mathrm{pH}$ solution," Journal of Materials Engineering and Performance, vol. 19, no. 6, pp. 834-840, 2010.

[5] Z. Guo, M. Zhao, C. Li, S. Chen, and L. Rong, "Mechanism of hydrogen embrittlement in a gamma-prime phase strengthened Fe-Ni based austenitic alloy," Materials Science and Engineering: A, vol. 555, pp. 77-84, 2012.

[6] H. Xin, J. A. F. O. Correia, and M. Veljkovic, "Three-dimensional fatigue crack propagation simulation using extended finite element methods for steel grades S355 and S690 
considering mean stress effects," Engineering Structures, vol. 227, Article ID 111414, 2021.

[7] H. Xin and M. Veljkovic, "Residual stress effects on fatigue crack growth rate of mild steel S355 exposed to air and seawater environments," Materials \& Design, vol. 193, Article ID 108732, 2020.

[8] Z. Li, X. Hu, M. Zhao, and L. Rong, "Effect of prior deformation on internal friction in a Fe Ni based austenitic alloy," Materials Letters, vol. 98, pp. 82-85, 2013.

[9] E. V. Chatzidouros, V. J. Papazoglou, and D. I. Pantelis, "Hydrogen effect on fracture toughness of API 5L X70, X65 and X52 pipeline steel welds: an overview," in Proceedings of the 30th International Conference on Ocean, Offshore and Arctic Engineering: American Society of Mechanical Engineers, Rotterdam, Netherlands, June 2011.

[10] P. Wang, Z. Lv, S. Zheng, Y. Qi, J. Wang, and Y. Zheng, "Tensile and impact properties of X70 pipeline steel exposed to wet $\mathrm{H}_{2} \mathrm{~S}$ environments," International Journal of Hydrogen Energy, vol. 58, pp. 1499-1512, 2015.

[11] S.-i. Komazaki, R. Maruyama, and T. Misawa, "Effect of applied cathodic potential on susceptibility to hydrogen embrittlement in high strength low alloy steel," ISIJ International, vol. 43, no. 4, pp. 475-481, 2003.

[12] J. A. F. O. Correia, A. M. P. De Jesus et al., "Modelling probabilistic fatigue crack propagation rates for a mild structural steel," Frattura ed Integrita Strutturale, vol. 31, pp. 80-96, 2015.

[13] J. A. F. O. Correia, A. M. P. de Jesus, and A. FernándezCanteli, "A procedure to derive probabilistic fatigue crack propagation data," International Journal of Structural Integrity, vol. 3, no. 2, pp. 158-183, 2012.

[14] D. Liao, S.-P. Zhu, and G. Qian, "Multiaxial fatigue analysis of notched components using combined critical plane and critical distance approach," International Journal of $\mathrm{Me}$ chanical Sciences, vol. 160, pp. 38-50, 2019.

[15] D. Liao, S. P. Zhu, J. A. F. O. Correia, A. M. P. De Jesus, and F. Berto, "Recent advances on notch effects in metal fatigue: a review," Fatigue \& Fracture of Engineering Materials \& Structures, vol. 43, no. 4, pp. 637-659, 2020.

[16] N. E. Nanninga, Y. S. Levy, E. S. Drexler, R. T. Condon, A. E. Stevenson, and A. J. Slifka, "Comparison of hydrogen embrittlement in three pipeline steels in high pressure gaseous hydrogen environments," Corrosion Science, vol. 59, pp. 1-9, 2012.

[17] D. Stalheim, T. Boggess, C. San Marchi et al., "Microstructure and mechanical property performance of commercial grade API pipeline steels in high pressure gaseous hydrogen," in Proceedings of IPC 2010 8th International Pipeline Conference Calgary, Alberta, Canada, September 2010.

[18] I. Moro, L. Briottet, P. Lemoine, E. Andrieu, C. Blanc, and G. Odemer, "Hydrogen embrittlement susceptibility of a high strength steel X80," Materials Science and Engineering: A, vol. 527, no. 27-28, pp. 7252-7260, 2010.

[19] E. J. Song, S.-W. Baek, S. H. Nahm, and U. B. Baek, "Notchedtensile properties under high-pressure gaseous hydrogen: comparison of pipeline steel X70 and austenitic stainless type 304L, 316L steels," International Journal of Hydrogen Energy, vol. 42, no. 12, pp. 8075-8082, 2017.

[20] M. Wasim and M. B. Djukic, "Hydrogen embrittlement of low carbon structural steel at macro-, micro- and nano-levels," International Journal of Hydrogen Energy, vol. 45, no. 3, pp. 2145-2156, 2020.
[21] A. Taha and P. Sofronis, "A Micromechanics approach to the study of hydrogen transport and embrittlement," Engineering Fracture Mechanics, vol. 68, no. 6, pp. 803-837, 2001.

[22] J. Shang, J. Zheng, Z. Hua et al., "Effects of stress concentration on the mechanical properties of X70 in high-pressure hydrogen-containing gas mixtures," International Journal of Hydrogen Energy, vol. 45, no. 52, pp. 28204-28215, 2020.

[23] Y.-h. Li, Q. Chi, H. Feng, H.-y. Chen, and X.-f. Xu, "Effect of strain aging on properties of X90 line pipe," Engineering Failure Analysis, vol. 118, Article ID 104844, 2020.

[24] X.-P. Niu, R.-Z. Wang, D. Liao, S.-P. Zhu, X.-C. Zhang, and B. Keshtegar, "Probabilistic modeling of uncertainties in fatigue reliability analysis of turbine bladed disks," International Journal of Fatigue, vol. 142, Article ID 105912, 2021.

[25] S.-P. Zhu, J.-C. He, D. Liao, Q. Wang, and Y. Liu, "The effect of notch size on critical distance and fatigue life predictions," Materials \& Design, vol. 196, Article ID 109095, 2020.

[26] D. Liao, S.-P. Zhu, B. Keshtegar, G. Qian, and Q. Wang, "Probabilistic framework for fatigue life assessment of notched components under size effects," International Journal of Mechanical Sciences, vol. 181, Article ID 105685, 2020.

[27] Y. Ai, S. P. Zhu, D. Liao et al., "Probabilistic modeling of fatigue life distribution and size effect of components with random defects," International Journal of Fatigue, vol. 126, pp. 165-173, 2019. 